\title{
Preface: A Note on Positionality
}

Throughout this book, you will find that I have included endnotes where I describe the choices I made, particularly in relation to language use and terminology. I do this in part because as a researcher I see my role more akin to museum curator than art critic. My influence is palpable throughout the book (e.g. in the structural choices I made, the ways in which I frame and group ideas and stories), but what I really want to do is to showcase the subject of the book: Mothers. Still, I start this book by sharing my story, the story of how I came to this work, to this country, to this research. I do this in Chapter 1. Here, I explain why.

My story is an important place to start for multiple reasons: my life experiences are what led me to the fields of bilingual education and special education. As an educator I have had the privilege of experiencing schooling from the stance of both a student and a teacher, from the lens of a daughter and a mother. More importantly still, I start with my story in recognition that we are in a moment in history when 'who you are' and 'who the world makes you out to be' need to be reconciled. It is important to share who I am in order for you, as a reader, to understand the women to whom this book is dedicated, the women whose stories fill the pages you are holding. It is important to understand that I arrived to this research from a place of longing, of emptiness - even if that was not evident to me when I started my doctoral journey or even when I first wrote the dissertation that would eventually result in this book - of wanting to see my mother's efforts, my sister's efforts as a young mother, my efforts as a racialized mother, every immigrant mother's efforts, every Black, indigenous, mother of color in the United States' efforts to be represented from a place of strength and appreciation. I do this in stark contrast to what my educational background conditioned me to believe: that mothers like mine, Black and Brown immigrants who didn't learn English fast enough, who were poor and working class, were empty vessels in need of filling. Over the years, mothers who are racialized as Black, indigenous, people of color, have been framed as welfare queens, and more recently, as public charges (Hancock, 2003; Weber, 2020). This book aims to chip away at those labels, to show the ways in which labels are mounted upon 
mothers as a way to devalue their contributions, as a way to rationalize the violence that is enacted upon them.

I start this book by telling you about who I am because it is essential to understanding why I chose to study, not what happens to children in schools but rather how what happens in schools reverberates through the home. Much of the academic scholarship that is written about mothers, Latinx mothers in particular, focuses on the ways in which schools can better support them and/or how schools can ensure that they are adequately equipped to support their children. All of this is written from a Western lens, a lens that evaluates Latinx mothers' contributions in relation to those of white mothers, which explains why another common lineage of education scholarship and research is grounded in explaining the cultural dynamics of Latinx families. Still, very little of this work is aimed at finding ways to make space for mothers' funds of knowledge, to make space for them, to ensure that their voices are heard. Most of it is aimed at explaining away their forced absence or to maximize the hidden labor that a school can extract from them. That is the literature that I consumed as a graduate student when working on my master's in science of education, when I was a classroom teacher and when I started my doctoral journey. I swam and waded through those waters long enough to realize that the voices that were missing from those readings were those of the mothers themselves.

In recent years, there has been an increasing push for scholars to state their positionality, to talk about who they are in relation to their work (Lin, 2015; Manohar et al., 2017). In part, this is done to ensure credibility, to ensure that the presentation of the data accounts for researcher bias. With that in mind, it would be easier and less cumbersome to simply write a positionality statement, one that informed you of my relationship to these groups: I am an immigrant, I grew up in the same neighborhood that these mothers are raising their children in, I was a teacher in a local community school, I attended the same church as some of them, we share a common language and, very significantly, we are all mothers. Perhaps it is for this reason that the mothers were so open with me, perhaps my presence and trustworthiness within the community allowed them to feel safe sharing their life with me. However, these points of communal convergence do not absolve me of bias because they also cloud the fact that we have distinct immigrant experiences because unlike many, if not all, of the mothers in this book, I navigate the world as a formally educated, middle class, multilingual, Black Latina who immigrated to the United States through chain migration in a distinctly different time; a time when nationalism wasn't as palpable, at least not to me. I am a mother who, while racialized and pathologized, also has access to spaces of overwhelming privilege. More importantly, this focus on my positionality erases their agency, their own sense of urgency to tell their story, their basic and human need to be heard. I share my story because who I 
am now is not who I always was, but who I am now is most certainly a product of all of the mothering and nurturing that I have received from traditionally devalued and discounted women.

I start with my story because who I am is embedded in every page you will turn; in every word you will read. I start with my story because, although unconsciously, when you saw my name on the cover of this book, you made assumptions about who I am and why I do this work. In this way, I also share my story because who you are will influence how you receive it. Ultimately, I share my story as an invitation to you: to be open to what you will read, to think about your positionality, to think about how you have upheld systems that devalue and discount mothers. I share my story because too often we allow numbers, titles and degrees to erase human lives. I share my story because part of me wanted to forget it, part of me wanted to fall into the American fold. I share my story, which is really the story of how I was mothered and how I mothered othered people's children, because without it, this book would not exist.

\section{References}

Hancock, A.-M. (2003) Contemporary welfare reform and the public identity of the 'welfare queen'. Race, Gender \& Class 10 (1), 31-59.

Lin, A.M.Y. (2015) Researcher positionality. In F.M. Hult and D.C. Johnson (eds) Research Methods in Language Policy and Planning (pp. 21-32). Chichester: John Wiley \& Sons Ltd. https://doi.org/10.1002/9781118340349.ch3

Manohar, N., Liamputtong, P., Bhole, S. and Arora, A. (2017) Researcher positionality in cross-cultural and sensitive research. In P. Liamputtong (ed.) Handbook of Research Methods in Health Social Sciences (pp. 1-15). Singapore: Springer. https://doi.org/10 .1007/978-981-10-2779-6_35-1

Weber, M.C. (2020) Of immigration, public charges, disability discrimination, and, of all things, hobby lobby. Arizona State Law Journal 52, 245. 